\title{
La problemática dimensión orgánica del cuerpo humano: sobre los limites entre la Analitica del Dasein de Martin Heidegger y el Análisis del Dasein de Medard Boss"
}

\author{
Felipe Johnson \\ Universidad de La Frontera
}

\begin{abstract}
Resumen: El presente trabajo se propone discutir acerca de los límites entre el Análisis del Dasein de Medard Boss y la Analítica del Dasein de Martin Heidegger. Tomando como punto de partida la aparición de la dimensión orgánica en las consideraciones de Boss, se discutirá cómo es que se devela una oposición en los énfasis temáticos correspondientes a una consideración filosófica y a una psicológica del ser humano. Dicha oposición será aclarada indagando en las respectivas motivaciones de ambos programas, para destacarlas como sus eminentes límites. Finalmente, comprendiendo dichas motivaciones como límites, el artículo planteará que la insistencia de lo orgánico vigente aún en Boss señalaria problemáticas que pueden competer aun a la Analitica del Dasein del mismo Heidegger.
\end{abstract}

Palabras clave: existencia; cuerpo vivo; cuerpo orgánico; limite; Heidegger; Boss

\begin{abstract}
The Problematic Organic Dimension of Human Body: on Limits Between Heidegger's Analitic of Dasein and Boss' Daseins Analysis". This paper aims to discuss the limits between Medard Boss' Daseins analysis and Martin Heidegger's Analytic of Dasein. Taking as starting point the appearance of human organic dimension by Boss' reflections, it will be discussed how an opposition comes to light between its respective thematic inflections, that is, by both philosophical and psychological considerations of human being. Thus, such opposition will be clarified delving into the motivations of both programs, to highlight them as its inherent limits. Finally, understanding these motivations as its limits, this paper proposes that this insistence of organics in Boss' psychology would point to problems which could still become relevant to Heidegger's existential analytic itself.

Keywords: existence; living body; organic body; limit; Heidegger; Boss
\end{abstract}

\footnotetext{
"Proyecto Fondecyt Regular n ${ }^{\circ}$ 1150034: "El cuerpo futuro: la posibilidad de vivir corporalmente en el mundo desde la temporalidad originaria del Dasein".
} 


\section{La reformulación existencial de la Psicología y el puesto de lo orgánico}

La analítica del Dasein es entendida en Ser y tiempo como la aclaración del existir humano en vistas al proyecto filosófico fundamental de plantear la pregunta por el sentido del ser $^{1}$. Como es sabido, una de las razones que justifica dicha pregunta radica en dejar abierta la posibilidad de una fundación ontológica efectiva de las ciencias ${ }^{2}$. En términos programáticos, se trataría de la constitución de una ontología fundamental que preparara a las ontologías regionales para una delimitación adecuada del campo de estudio de las ciencias positivas. Un programa fundacional, dicho sea de paso, que el mismo Heidegger, luego de Ser y tiempo, en 1928, denominará concretamente "metaontología" (Metontologie) ${ }^{3}$. Esta será entendida como el ámbito de comprensión del ser del ente del cual se ocuparian las ciencias positivas, en tanto una articulación $a$ prioriy, por ende, del todo ajena al ejercicio de establecer un concepto general, resultado de una suerte de sumatoria de los diversos conocimientos empíricos obtenidos por la misma ciencia ${ }^{4}$. Dicho plan fundacional, que implicaria una reformulación del campo de estudio de la psicología en su totalidad, es el que pareciera estar comenzando en los diálogos entre Martin Heidegger y Medard Boss. En Zollikoner Seminare se rinde cuenta de advertencias que realizará Heidegger a un grupo de psiquiatras para conducirlos hacia una confrontación con aquellos conceptos fundamentales que delimitarían aquella experiencia del hombre en la cual se mueven y que repercutirian en el trato mismo que ellos mantienen con los seres humanos individuales. Se trata de una fundamentación de la psicología que continuará en ejercicio en la posterior obra del mismo Boss con el interés último de intervenir en los individuos particulares según lo que este concebiría como el Análisis del Dasein ${ }^{5}$.

Cf. Heidegger, M., Sein und Zeit, Tübingen: Max Niemeyer Verlag, 2001, p. 17.

2 Cf. ibid., p. 11.

3 Cf. Heidegger, M., Metaphysische Anfangsgründe der Logik, Fráncfort d.M.: Vittorio Klostermann, 2007, p. 199.

4 Cf. ibid., p. 199ss.

5 Para identificar los proyectos de Heidegger y Boss, tomaremos la distinción que Heidegger comenta en Zollikoner Seminare entre la "Analitica del Dasein" (Daseinsanalytik), refiriendo a su propio proyecto filosófico, y "Análisis del Dasein" (Daseinsanalyse), utilizado para su recepción en la psiquiatria, primero como una "psychiatrische Daseinsanalyse", por Biswanger, pero que, en relación a Boss, pasa a ser una "therapeutische Daseinsanalyse", y que traduciremos abreviadamente como "Análisis del Dasein" ( $c f$. Heidegger, M., Zollikoner Seminare, Fráncfort d.M.: 
Es lo que se advierte en la reformulación que realizara Boss del tradicional problema de lo psicosomático, tema central en toda consideración psicológica. Y es que tal problemática devela que el ser humano no está libre de quedar embargado en contextos de la más profunda desorientación y dolor vitales. Los así llamados trastornos psicosomáticos, así como las enfermedades somatogenéticas, testimonian que la individualidad humana posee una concretud vulnerable y que es ella en razón de la cual psicólogos y psiquiatras se ven exigidos a aclarar sus propios conceptos. Es en este ámbito donde términos como psyche y sóma y la tradicional relación del alma con el cuerpo, entran en juego como recursos para abordar la condición humana particular, de modo que el terapeuta disponga de las nociones necesarias para regresar a la vida sana al existir preso en sus propias dolencias.

En este contexto, se vuelve comprensible que Boss advirtiera la necesidad de recurrir a un pensar cuya pretensión sea comprender al existir humano en su auténtica facticidad, como sería el caso de la Analítica del Dasein de Heidegger. Empero, pese a que las nociones heideggerianas parecen serle productivas, su tarea no deja de mostrar determinados límites respecto de tal programa filosófico. La paradoja parece ser, en efecto, que precisamente en aquel pensar donde Boss vislumbrara la oportunidad de ganar un terreno conceptual adecuado para la praxis psicológica es donde, a la vez, parece albergarse cierta resistencia de ser asimilado íntegramente por esta disciplina. En concreto, parece ser que el énfasis existencial de la corporalidad en el contexto heideggeriano

\footnotetext{
Vittorio Klostermann, 1994, p. 162 y Becker, G., Philosophische Probleme der Daseinsanalyse von Medard Boss und ihre praktische Anwendung, Marburgo: Tectum Verlag, 1997, p. 85). Pese a que el presente trabajo se centrará en la relación puntual entre Boss y Heidegger, cabe señalar que la adopción de la filosofia de este último en la psicologia ha asumido diferentes configuraciones. En la época de Zollikoner Seminare, en los años 50, Binswanger ya había desarrollado una psiquiatria daseinsanalitica. Sin embargo, siendo decisivas las diferencias de Heidegger con sus postulados ( $c f$. Heidegger, M., Zollikoner Seminare, pp. 150-151 y p. 239), la recepción de Medard Boss parecía representar la manera autorizada por el filósofo para entender cómo la psicología podría dialogar con su analitica existencial ( $c f$. Askay, R., "La filosofia de Heidegger y sus implicaciones para la Psicologia: Freud y el psicoanálisis existencial”, en: Gaceta Universitaria, n. 2 (2006), p. 182). Mientras que en países como Francia, la línea psiquiátrica iniciada por Binswanger es recepcionada y difundida por autores como Maldiney ( $c f$. Dastur, F. y P. Cabestan, Daseinsanalyse, París: Vrin, 2011), en Suiza emergerá una corriente terapéutica daseinsanalítica a cargo de los discípulos del mismo Boss, como fue Gion Condrau. Actualmente siguen apareciendo intentos de incorporar los postulados heideggerianos en la psicología. Entre ellos destaca Alice Holzhey-Kunz, quien iniciara una "hermenéutica psiquiátrica", y Petr Kouba, quien propone desligar la comprensión de trastornos psiquiátricos de los postulados de Ser y Tiempo, como lo haría Binswanger, y de los de Zollikoner Seminare, como en el caso de Boss, para situarse en las lecturas heideggerianas sobre Hölderlin, en el giro de su pensar ( $c f$. Kouba, P., Geistige Störung als Phänomen. Perspektiven des heideggerschen Denkens auf dem Gebiet der Psychopathologie, Würzburg: Königshausen \& Neumann, 2012).
} 
trae consigo una decidida omisión de la dimensión orgánica del hombre que, para la psicología y su tratamiento efectivo de trastornos psicosomáticos, no es y no puede ser sin más prescindible.

Y es que, como Heidegger advirtiera en Zollikoner Seminare: "El cuerpo vivo (Leib) no es ninguna cosa, ningún cuerpo cósico (Körper), sino que cada cuerpo vivo, esto es, el cuerpo vivo en cuanto cuerpo vivo es cada vez mi cuerpo

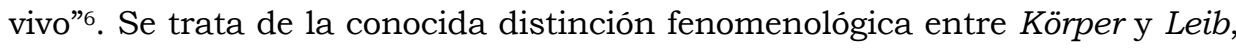
dos conceptos que resultaron del todo fecundos para emprender un acceso adecuado al fenómeno total de nuestro existir corporal. Mientras que el término Körper señalara una experiencia del cuerpo en un sentido objetual, esto es, en tanto que instancia meramente cósica, Leib acentuaba su íntima vitalidad, su carácter existencial, sentido y fáctico. Sin embargo, es dicha distinción la que terminará por heredar dificultades en la investigación psicológica daseinsanalítica, como es el hecho de verse obligada a insistir en la relevancia de lo orgánico-corporal como una instancia que, si bien puede ser considerada como objetuada, tendría interés aun en la medida en que se le aborde como medio para ganar una comprensión de nuestra relación corporal en cuanto experienciada existencialmente ${ }^{7}$. En tal consideración se advierte que para la terapia daseinsanalítica no resulta simple dejar de lado lo orgánico ya que, entendido como un ámbito de procesos anónimos, puede también ser accesible superando su condición de mero objeto, en lo que se denominaría un "Gestaltleib" a la manera de un cuerpo lleno de un sentido existencial futuro9. Así, con la recepción de las consideraciones heideggerianas, la terapia daseinsanalítica se verá exigida de aclarar cómo es que el cuerpo orgánico sí sería una dimensión a considerar, en cuanto ámbito innegable y propio de la actividad médica ${ }^{10}$.

A nuestro juicio, la dificultad que ahora presenta la aparición de la dimensión orgánica en las consideraciones psicológicas acusa sus límites con el pensar filosófico de Heidegger. Y tal problema no solo tiene interés para la psicología, sino que es, a la vez, una exigencia para la propia filosofia, puesto que implica ante todo que una consideración existencial del cuerpo humano en cuanto asunto eminentemente filosófico sea aclarada en su propio sentido y tendencia tematizante. Por ello, la pregunta en el contexto de esta recepción

6 Heidegger, M., Zollikoner Seminare, p. 113.

Cf. Stüttgen, T., "Zur Unterscheidung von Körperlichkeit und Leib", en: Daseinsanalyse: phänomenologische Anthropologie und Psychotherapie, 7 (1990), p. 269.

8 Ibid.

9 Cf. ibid., p. 257.

${ }^{10}$ Cf. ibid., p. 269. 
psicológica de la Analítica del Dasein heideggeriana puede seguir expresándose en cuáles serian, en última instancia, los criterios para comprender la exclusión de lo orgánico en una tematización filosófica respecto del hombre, como la de Heidegger, y si estos criterios son también válidos para la psicología ${ }^{11}$. Nuestro interés será, por ello, problematizar la aparición de la dimensión orgánica del ser humano a propósito del diálogo entre Heidegger y Boss, para discutir cómo es que desde ella se hace posible detectar finalmente la naturaleza de sus mutuos límites. Como quisiéramos señalar, lo orgánico se presenta como problema solo en el contexto de determinadas precisiones metódicas que distinguirian las naturalezas tanto de la reflexión psicológica como de la propia filosofia heideggeriana. Para comenzar, abordaremos los puntos centrales en los planteamientos de Boss acerca de lo psicosomático, de manera que su posición sirva de punto de partida para develar los aspectos heideggerianos presentes en ellos, y así ganar un primer suelo temático para destacar, ante todo, en qué sentido podemos hablar de sus límites y, con ello, destacar a su vez en qué sentido la problemática aparición de lo orgánico en el Análisis del Dasein de Boss puede implicar ciertas tareas para la propia analítica existencial heideggeriana.

\section{Lo psicosomático en Boss: la urgencia de una comprensión unitaria del ser humano}

Será en la obra Fundamentación existencial de la Medicina y la Psicología (1971) donde se sistematizará el esfuerzo de Boss por trasladarse a una perspectiva que permita entender las patologías psiquiátricas como situaciones

\footnotetext{
${ }^{11}$ Sin embargo, afirmar que en Heidegger habria una exclusión de lo orgánico en el hombre, no quiere decir que este no se haya ocupado con esta temática. Será en su lección del semestre de invierno (1929/30), Die Grundbegriffe der Metaphysik, (Cf., Heidegger, M., Die Grundbegriffe der Metaphysik: Welt-Endlichkeit-Einsamkeit, Fráncdort d.M., 2004, §53), donde se detendrá en el concepto de órgano en tanto que "condición de estar tomado" (Benommenheit) (ibid., p. 376) por su entorno. Empero, cabe señalar que las discusiones sobre la esencia del organismo ahí efectuadas servirán para desentrañar el sentido de la tesis de lo animal en tanto que "pobre de mundo", en el intento, advierte el mismo Heidegger, de mantener estas reflexiones en una relación concreta con la biología (cf. ibid., p. 389). En este contexto, la aclaración de lo humano como "constructor de mundo" (Weltbildend), seguirá una vía distinta a una consideración de lo orgánico, a saber, entendiendo al existir en tanto que "apertura del ente en cuanto ente" (ibid., p. 398), manteniéndose, así, en sus tesis del Dasein en cuanto movimiento de apertura del ahí, como se discurirá más adelante. Ahora bien, como antecedente de las consideraciones que Heidegger realizara en la mencionada lección acerca del organismo, es importante tener en cuenta la delimitación del mismo explicitada en su lección de 1924 sobre la filosofia aristotélica. En ella se le determina, en efecto, como el "ente que tiene el carácter de la capacidad (Leistung), que en sí mismo está orientado a ser hacia un fin" (Heidegger, M., Grundbegriffen der aristotelischen Philosophie, Fráncfort d.M: Vittorio Klostermann, 2002, p. 238).
} 
vitales. Los análisis se realizarán a propósito de una de las pacientes tratadas por el mismo psiquiatra. Se trata de Regula Zürcher ${ }^{12}$, una mujer víctima de numerosas perturbaciones que brindarian la oportunidad de reinterpretar una problemática que, a juicio de Boss, ni la óptica fisiológica ni la psicoanalítica parecen tratar convenientemente: los trastornos psicosomáticos.

Durante sus años de matrimonio, la mujer habría sido dependiente de la vida sexual cultivada con su marido mas, luego de su separación, habría quedado confinada al cuidado exclusivo de su hija. Tras un tiempo de atención abnegada hacia la niña, se habrian manifestado fuertes impulsos de estrangularla y apunalarla ${ }^{13}$. Por otra parte, durante el período de su terapia daseinsanalítica, la mujer habría comenzado a sentirse atraída por un joven pero, entendiendo al sexo opuesto como algo "extremadamente indecente, prohibido, peligroso, criaturas pecaminosas" 14 , habría reprimido sus deseos sexuales hasta que acaecerian trastornos corporales como la parálisis de su pierna, calambres intestinales y diarreas ${ }^{15}$. Lo que Boss deberá objetar en este caso es la suposición de eventuales fuerzas endopsíquicas, esto es, estructuras inconscientes que jugarian aquel rol inhibitorio de su deseo sexual. Tales entidades, sentencia Boss, "no son más que invenciones indemostrables y arbitrarias"16. Los fenómenos psicosomáticos, por tanto, deberán comprenderse al margen de una relación entre consciente e inconsciente y ajenos a categorías fisiológicas, como si en el caso de las diarreas el problema radicara en la "acción de efectos depresivos sobre los centros autónomos del córtex cerebral”"17.

Las patologías psicosomáticas no serian un hecho meramente fisiológico, ni el producto de una psyche que, entendida como una substancia autónoma del sóma, influyera sobre este según una relación causal oscura. Precisamente, es la noción de causalidad aquella que acusa su evidente problematicidad como recurso para explicar los fenómenos referidos. En su trabajo La concepción de hombre en las ciencias naturales y el Análisis del Dasein, y en estrecha relación con las advertencias de Heidegger, Boss delatará un así llamado "proceso histórico de tecnificación" ${ }^{18}$ que habría determinado el destino de ciencias como

${ }^{12}$ Cf. Heidegger, M., Zollikoner Seminare, p. 199.

${ }^{13}$ Cf. Boss, M., Existential Foundations of Medicine and Psychology (Conway, S. y A. Cleaves, trads.), Nueva York/Londres: Jason Aronson, 1983, pp. 169-178.

${ }^{14}$ Ibid., p. 180.

${ }^{15}$ Cf. ibid, pp. 179-182.

${ }^{16}$ Ibid., p. 181.

${ }^{17}$ Ibid., p. 183.

${ }^{18}$ Boss, M., "The Conception of Man in Natural Science and Daseinsanalysis", en: Comprehensive Psychiatry: Official Journal of the American Psychopathological Association, 3/4 (1962), p. 199. 
la biología, la psicología y la medicina. Esto es, un eventual triunfo del método matemático prescribiría una concepción del mundo bajo la lógica de una ciencia como la física o, más exactamente, la mecánica ${ }^{19}, \mathrm{y}$, bajo su dominio, sería precisamente la ley de causalidad aquella que se infiltraría definitivamente en el estudio de lo humano, como legalidad calculable ${ }^{20}$.

Justamente, el mencionado "proceso histórico de tecnificación" se constituiría en el horizonte para comprender la actual noción de imágenes mentales utilizada por la propia psicología. Mientras que en un principio el ente real sería comprendido por los griegos como un "simple aparecer" (phainesthai), posteriormente pasará a ser planteado por Descartes en los términos de un "ob-jectum" para la res cogitans. El cogitare mismo sería concebido como un acto eminentemente productivo de la objetualidad del objeto que aparece ${ }^{21}$. Y es que con la traducción latina del vocablo griego érgon en opus, la concepción de "objeto percibido", esto es, de la realidad que se muestra a la vida humana, no pudo sino ser comprendida como la obra, es decir, como el producto de la laboriosa operación de fuerzas anímicas, vale decir, de los actos mentales del sujeto ${ }^{22}$.

Ahora bien, pese a la intención de desligar lo psíquico de las leyes del mundo mecánico y físico, para acentuar la dimensión subjetiva como instancia fundamental de la constitución de la realidad humana, el psicoanálisis habría sucumbido también a la noción de producción y de eficiencia instaurada por Descartes y, por ende, seguiría siendo deudor de la noción de subjetividad en tanto que fuerza productora. Tal comprensión es la que dominaría la pregunta por lo psicosomático, en términos de una relación causal, a la cual subyacería la idea de efectuación como modo de explicar la eventual relación entre dos substancias constitutivas de lo humano como serian lo psíquico y lo somático ${ }^{23}$.

\footnotetext{
19 Cf. Heidegger, M., Zollikoner Seminare, p. 217.

${ }^{20}$ Cf. ibid., p. 262. En este contexto, Boss destaca que la biología jamás habría podido dejar de comprender la vida en términos de la eficiencia propios de la época moderna mecanicista ( $c f$. Boss, M., "The Conception of Man in Natural Science and Daseinsanalysis", p. 195). Y esto, pese al surgimiento del vitalismo, en la segunda mitad del siglo XVII, que postulara fuerzas no reductibles a lo mecánico, pues estas seguirian siendo entendidas como "causas eficientes" de lo vivo ( $c f$. ibid., p. 196). Por lo demás, en reacción al carácter especulativo de dicho vitalismo, pensadores de mediados del siglo XIX, como Helmholtz, Darwin, Fechner, resituarian a la biología en un materialismo filosófico ( $c f$. ibid.). Sería Driesch, ya en el siglo XX, quien defenderá un neovitalismo. Empero, su noción de "fuerzas finales" no acabaría por abandonar la idea moderna de causa eficiente (cf. ibid., p. 199). Así, pese a las posiciones antagónicas en la historia de la biología, el proceso de tecnificación de la vida que Boss intentara delatar, jamás se habría visto interrumpido. ${ }^{21}$ Cf. ibid., p. 194.

22 Cf. ibid., p. 195.

${ }^{23}$ Cf. ibid., p. 204. Asimismo, cf. Boss, M., "The Ego? Human Motivation?", en: Acta Psychologica, 19 (1961), p. 218.
} 
Así, Boss comprenderá que una aclaración del ser del hombre sería requerida como fundamento para abordar el problema de fenómenos humanos concretos, pudiendo proteger a la psicología de aquella noción de lo psicosomático que ocultaría su auténtico modo de $\operatorname{ser}^{24}$. Por ende, la aludida tecnificación en la concepción del ser humano, y su inherente dominio de la ley de causalidad, acusaría la urgencia de recurrir a la Analítica del Dasein. En efecto, mientras que la dicotomía alma-cuerpo sería completamente artificial ${ }^{25}$, concluye Boss, el ser humano deberá entenderse como "la unidad primaria e inseparable de la existencia iluminadora, como apertura de mundo que resplandece de modo inmediato en su luz, es decir, en todos los fenómenos del mundo con todas sus referencias significativas" 26 .

Se advierte, entonces, la primera ganancia por parte de Boss de las reflexiones heideggerianas. La pretensión última de desligar la consideración de lo humano de una noción objetivante, que solo conduciría a comprender sus dimensiones constituyentes en una relación gobernada por la ley de causalidad, es la que parece predisponerle a la recepción de una concepción que superaría toda eminente escisión en la naturaleza humana para concebirla en tanto que unidad primigenia. Dicho pensar es el que brindaría las condiciones comprensivas necesarias para resolver aquella dificultad que emerge desde la noción tradicional de hombre, a saber, cómo es posible explicar aquella relación entre lo corporal y lo psíquico, que para el psiquiatra y el psicólogo es un hecho suficientemente acreditado en la aparición de estos trastornos psicosomáticos con los cuales ha debido confrontarse en su praxis médica.

No obstante, pese a que la psicología pareciera hallar una salida respecto de este apremiante problema psicológico, la consideración existencial heideggeriana dejará abierta la puerta para ingresar a uno nuevo. Este se puede formular así: si con ella se trata de comprender al ser humano como un fenómeno unitario, al margen de cualquier tipo de dualidad cuerpo-alma,

\footnotetext{
${ }^{24}$ Una exposición extensa de las críticas de Boss al psicoanálisis pueden ser halladas en su obra Der Traum und seine Auslegung (1953). En ella se afirma que la noción freudiana de impulso, así como la de arquetipo de Jung persistirian en la idea de eficiencia y productividad moderna. Sus postulados, a juicio de Boss, no serían más que abstracciones que, entendidas como motores de los sueños, delatarian que ambos continúan en el "camino del pensamiento técnico de las ciencias naturales" (Boss, M., Der Traum und seine Auslegung, Bern/Stuttgart: Hans Huber, 1953, p. 63). Por esta vía, Boss revisará críticamente escuelas derivadas del psicoanálisis, como la neopsicoanalítica de Harald Schulz-Hencke ( $c f$. ibid., p. 64) y el "neofreudismo" de Erich Fromm (cf. ibid., p. 67).

${ }^{25}$ Cf. Boss, M., "The Conception of Man in Natural Science and Daseinsanalysis", p. 212.

26 Ibid., p. 212.
} 
para entender el despliegue del existir en tanto que ser-en-el-mundo, ¿cómo le puede resultar legítimo al psicólogo, es decir, a aquel que se confronta con seres humanos individuales, considerar desde el pensar de Heidegger aquella dimensión orgánico-material humana que en efecto le sale al paso en su propia praxis? ¿No parece ser así que la perspectiva existencial que entiende al ser humano como fenómeno unitario obligaría a omitir una dimensión que es válida de considerar solo en el interior de aquella escisión tradicional entre alma y cuerpo, que Heidegger mismo rechazara? Así, mientras Heidegger afirma en Ser y tiempo: "la 'substancia' del hombre no es el espíritu, en cuanto la síntesis del alma y del cuerpo, sino la existencia" 27 , será la aparición del problema del cuerpo en estas discusiones psicológicas la que da lugar a advertir la complejidad de esta nueva problemática que emergerá para la psicología en el contexto de una reformulación que se ha decidido por adoptar las consideraciones existenciales de Martin Heidegger.

\section{La noción de cuerpo en Boss: la dimensión orgánica como resto pendiente}

A modo de ilustración de lo que mentaría su noción existencial de cuerpo, el psicólogo recurrirá primero a una experiencia personal. Boss, reza su relato, se encontraria en su jardín, absorto en diversos pensamientos. Se hallaría observando aquel entorno familiar que caracteriza su hogar, "existiendo en tanto una responsividad que despliega mundo"28. Mientras tanto, se arrojaria a reflexiones sobre tópicos de la medicina, para luego ser conducido a su pasado. Así es como sobrevendrían recuerdos de conversaciones con sus colegas y desde ahí, sus reflexiones le llevarian al semestre entrante, prestando atención a su futuro próximo. Hasta ese momento, según Boss lo describe, su ser-en-el-mundo pareciera extenderse más allá de los límites cuantificables espacio-temporales, para situarse en horizontes de su situación vivida, como su presente, su pasado y su futuro. No obstante, el repentino colapso de la silla en la cual se hallaría, provocará la lesión del dedo de su mano, sumiéndolo en un dolor tal que el pasado, futuro y presente, hacia los cuales su existir se expandía, se reducirian ahora a rehuir del dolor sufrido en el accidente. Empero, explica este, no es que un objeto "psyche" se haya alterado, lo que en términos existenciales ocurriría es que "lo que se ha cambiado y resintonizado

27 Heidegger, M., Sein und Zeit, p. 117.

28 Boss, M., Existential Foundations of Medicine and Psychology, p. 210. 
es, más bien, la apertura perceptiva del ser en el espacio y el tiempo, que es la esencia de mi Da-sein"29.

Entonces, en el caso de un Boss que intenta repensar el fenómeno del cuerpo desde Heidegger, la solución es entender que los límites de una relación existencial configuran además los limites del ser corporal humano. Las reflexiones de Boss se nutren de aquellas aclaraciones heideggerianas sobre el Dasein y sobre el modo como su carácter ek-stático delimitaría también al cuerpo $^{30}$. En efecto, el esfuerzo de Boss será describir la corporalidad según la apertura del ser-en-el-mundo, desligándola de la idea de una eventual estructura en sí para destacar que los auténticos límites corporales no acaban ni en su figura anatómica, ni se extienden desde ahí hacia un mundo exterior ${ }^{31}$. En el acto de señalar una ventana, explica Boss al igual que Heidegger, no es que se proyecte una relación que comience desde el dedo hasta la ventana indicada, sino que los límites del cuerpo ek-stático se hallan en la extensión del ser-enel-mundo ${ }^{32}$. El cuerpo, para Boss, ya está ahí afuera, es decir: "los límites de mi corporalidad coinciden con aquellos de la apertura al mundo"33.

La corporalidad humana, como se advierte, sería una que pertenece ante todo a aquella relación existencial primaria que abre mundo, siendo esta última el horizonte en el cual aquella puede acaecer. Y en este mismo sentido, el hecho de que los limites del cuerpo existencial no se confundan con los límites del cuerpo anatómico es un índice para entender el fenómeno del cuerpo desvinculado de raíz de una noción orgánico-material. Así, la parálisis de la pierna o los trastornos intestinales de Regula Zürcher, lejos de abordarse como un influjo causal de una psyche en el sóma, señalarán que lo que ocurre a nivel de su organismo radica en una reducción del ser cuerpo del propio existir, en cuanto relación eminentemente existencial. Aquellos impulsos de agredir a la niña pueden ser entendidos, en efecto, como la reducción de las posibilidades según los cuales la mujer puede ejercer el amor ${ }^{34}$. Tal reducción del ser-en-elmundo de Regula Zürcher daría paso a lo que podría entenderse como la constricción de su propio cuerpo. Por esta vía, la parálisis de su pierna deberá ser interpretada como una pérdida de la relación de Regula Zürcher con su propia

${ }^{29}$ Ibid., p. 211.

${ }^{30}$ Cf. Heidegger, M., Zollikoner Seminare, p. 256.

${ }^{31}$ Cf. ibid., pp. 112-113 y p. 232.

${ }^{32}$ Cf. Boss, M., Existential Foundations of Medicine and Psychology, p. 102.

33 Ibid., p. 103.

${ }^{34}$ Cf. ibid., p. 173. 
corporalidad, en el sentido de una restricción de sus posibilidades de ser mujer ${ }^{35}$. Así, entonces, "ser mujer" denominaría a aquella relación existencial que es su dimensión corporal. En dicho caso se anuncia, por tanto, la pertenencia de la corporalidad, existencialmente entendida como una relación, intimamente determinada en sus auténticos límites por aquellos del existir íntegro.

Hasta acá la dimensión corporal humana es tratada en directa relación con la unidad originaria que es el Dasein. El cuerpo pasa a ser replanteado en el sentido específico de una relación, una t que está en esencia "ahí fuera", en aquel mundo que el Dasein mismo abre. Este es el planteamiento que parece guiar el relato del mismo Boss como el de Regula Zürcher. En el primero, la relación corporal se hallaría reducida a su propio dolor, y en ese mismo contexto, el mundo hacia el cual tal relación se dirige vitalmente se presentaría igualmente restringido en el sufrimiento. En el caso de Regula Zürcher, su relación corporal, caracterizada como "ser mujer", solo parece confrontarse con los límites en aquel mundo abierto según una comprensión precisa del otro "masculino" en tanto que "repudiable", constituyéndose así un existir corporal subordinado a los límites de su propia apertura de mundo. Con todo, pareciera que la perspectiva unitaria del existir hallada en los planteamientos heideggerianos permitiría abandonar la pregunta por una relación causal supuesta desde la escisión clásica de lo humano. Desde esta nueva óptica, se trata de explicitar aquellos límites existenciales en los cuales un mundo y una relación fáctica con el mismo, como resulta ser el "ser corporal", se despliegan.

No obstante, atendiendo nuevamente a Boss, cabria examinar si sus consideraciones existenciales han resuelto definitivamente la problemática escisión clásica. En efecto, este no parece ser el caso, como se puede apreciar cuando todavia se reconoce un influjo de las condiciones orgánicas en el propio ser-en-el-mundo individual. Enfermedades somatogenéticas, como la diabetes o el daltonismo, por ejemplo, se expresarian para Boss como reducciones de determinadas posibilidades que la vida sana puede realizar ${ }^{36}$. En otro caso, Boss dirá: "un niño que ha sufrido un daño prenatal a causa de tamilomida y viene al mundo sin brazos está, por una parte, directamente afectado en su habilidad de saludar a la gente. Él no puede estrechar la mano; él ha sido escindido de esta manera de relacionarse con otros. El Da-sein de un niño nacido con brazos, aunque incapaz de usarlos, debido a una parálisis congénita, ha

35 Cf. ibid., p. 185.

${ }^{36}$ Cf. ibid., p. 203.

ARETÉ Revista de Filosofia, vol. XXIX, № 2, 2017 / ISSN 1016-913X 
sido arrebatado con igual eficacia de su habilidad de ejecutar corporalmente la relación de saludar"37.

¿No parece que tal formulación resulta problemática si la motivación de fondo es la de integrar las instancias humanas según una concepción unitaria del Dasein? Como se advierte, en la cita parecieran distinguirse ahora tres dimensiones que, a su vez, deberian comprenderse en conjunto. Por una parte, destaca el ser-en-el-mundo mismo del niño en cuanto existente. Y en relación con ello, figura esa "relación de saludar", que es aquella que ha sido privada, y que debería ser entendida, por tanto, como su dimensión existentiva corporal. En este caso, el ser-en-el-mundo total del niño y la relación corporal de "saludar", es decir, un "estar con el otro" al modo del "saludo", pueden entenderse en una íntima unidad. Sin embargo, también aparece en la advertencia de Boss la ausencia del brazo, esto es, de la dimensión eminentemente física, y es la carencia del miembro la que no termina por aclararse completamente. En efecto, fenómenos como trastornos histéricos o las enfermedades somatogenéticas siguen haciendo explícita una dimensión orgánica que, pese a la pretensión de superar la escisión de una psyche y un sóma, parece seguir quedando sin ser integrada definitivamente al fenómeno unitario del Dasein.

Por un lado, entonces, se destacaba que, si el ser cuerpo que Boss describe radica en una relación existencial, tal noción parecía señalar hacia una dimensión humana distinta a la eminentemente orgánica, para lograr asî dar solución a la escisión entre alma y cuerpo. Mas, en la medida en que lo orgánico continúa acusando su presencia en determinadas patologías, permanece siendo problemática su relación con el movimiento existencial que Boss ha decidido asumir desde la Analítica del Dasein heideggeriana. En otras palabras, el problema que permanece tras esta formulación continuará siendo cómo es que la instancia orgánica que sigue acusándose puede ser ahora entendida como perteneciente al movimiento existencial que es el Dasein mismo, de tal manera que la investigación psicológica no desemboque en aquel dualismo alma-cuerpo negado en las propias consideraciones heideggerianas.

Así, en el contexto de los planteamientos psicológicos de Boss es posible advertir cómo es que esta dimensión orgánica persiste en sus interpretaciones como un resto pendiente que, pese a ser entendido en una pertenencia al ser del hombre en tanto que Dasein, no termina por ser incluido al mismo de manera que su unidad originaria se exprese cabalmente. Este es un hecho decisivo en las

37 Ibid., p. 201. 
presentes reflexiones. Es dicha persistencia de lo orgánico en una psicologia que pretende adherir las tesis heideggerianas la que parece obstaculizar la pretendida reformulación existencial desde la cual el cuerpo humano debiera plantearse en cuanto Leib y no como Körper. Así es como tal persistencia de lo orgánico se acusa como un claro impedimento para una fundamentación existencial de la psicología en términos heideggerianos. Sin embargo, a nuestro juicio, lo que acá se acusa es un problema más de fondo, y en relación con que a la psicología misma parecen subyacer determinadas tendencias interpretativas ajenas a la perspectiva heideggeriana y, quizás, a la filosófica en general. Como se ve, quizás sea esta última advertencia la que conduzca a la auténtica dificultad que está en juego en la recepción de la Analítica del Dasein en la psicología que pretende replantear Medard Boss. Para destacarla deberemos examinar ahora el sentido de las consideraciones que hará Heidegger sobre el cuerpo humano.

IV. La pertenencia ontológica de lo orgánico al existir: una aclaración metódica

El problema de lo físico-orgánico no es pasado por alto en Zollikoner Seminare. Heidegger dirá: “... todo lo nuestro que se dice corporal material brota inmediatamente de las posibilidades de percibir y del comportarse que en realidad no son aprehensibles materialmente, en las cuales consiste nuestro $D a$-sein conforme a su esencia. Esta perspectiva permite concebir sencillamente cómo pertenece inmediatamente y sin límites todo lo corporal al existir y de qué modo de ser es y permanece" 38 . En este contexto, se afirmará también que "hasta la última molécula hormonal pertenece de modo esencial al existir (Existieren)" 39 . Y asumiendo tal tesis, Boss reiterará que "hasta el interior de la última fibra nerviosa se configura y es contenida en la determinación esencial de lo que se debe llamar el Dasein humano"40.

Se alude aquí a una "pertenencia" de lo corporal, esto es, material, al existir. Una pertenencia que podria entenderse en términos de que esas "posibilidades del percibir y del comportarse" que el Dasein es, son el horizonte de la dimensión orgánica. No obstante, la acotación de Boss agrega un nuevo matiz. Según su formulación, aquella apertura de mundo "contendría" la dimensión orgánica, otorgándole el carácter de vivo que deviene de la naturaleza propia del Dasein mismo. Así, la pregunta será cómo entender dicho "estar contenido"

\footnotetext{
${ }^{38}$ Heidegger, M., Zollikoner Seminare, p. 296.

39 Ibid., p. 293.

40 Ibid., p. 296.
} 
por parte de la dimensión orgánica. ¿Consiste en ser gobernada, dominada, por algo distinto a ella? A nuestro juicio, tal formulación es susceptible de ser entendida como si hubiese un oscuro influjo de una instancia ahora "espiritual" sobre la dimensión física humana. Lo físico seguiría siendo un anexo que, por su parte, no puede sin más dejarse de lado en las consideraciones, pues este influiría también en el existir. Y, sin embargo, es una afirmación de este tipo la que resulta completamente inconciliable con la analítica existencial del Dasein ${ }^{41}$.

Se deberá entender, entonces, qué se quiere realzar cuando se toma al cuerpo en tanto que Leiby cómo es que a este le "pertenecería" lo orgánico. Para ello es necesario atender a que en las consideraciones de Heidegger lo orgánico sí ha de ser descartado desde el comienzo. Es lo que se observa en sus lecturas sobre Kant. Cuando este delimita el correcto sentido de una interpretación de la sensibilidad, advierte: "Para la esencia de la sensibilidad, entendida filosóficamente, no es decisivo que junto a ella operen los cinco sentidos mediante determinadas herramientas. De tal investigación Kant no participa en absoluto, y ciertamente con razón, pues la esencia de la sensibilidad no radica en los órganos de los sentidos, sino en que la sensibilidad, primero, es donadora de intuición y, segundo, es intuición finita" ${ }^{\text {"2 }}$. Así, la exclusión de lo orgánico aparece en las consideraciones de Heidegger como una decisión expresa en su intento de identificar el auténtico carácter filosófico de una consideración. La sensibilidad deja de plantearse referida al conjunto de órganos perceptivos, valorando que la investigación kantiana se halla correctamente orientada al auténtico fenómeno desligándose de los mismos. Según lo anterior, resulta comprensible su esfuerzo por desvincular al Dasein de la noción material, esto es, cósica, en cuanto no parece ser propia de una reflexión filosófica.

\footnotetext{
${ }^{41}$ Como se advierte, el problema sigue siendo acá, en qué medida una consideración del cuerpo en tanto que orgánico puede resultar fructífera para una determinación de la esencia del existir y, en relación con la psicología que pretenda fundamentarse en la analítica del Dasein, la pregunta sigue siendo: ¿bajo qué respectos, y en qué sentido propiamente existencial puede el cuerpo aparecer en sus propias consideraciones? Será el mismo Heidegger quien comenta: "Que la fisiología y la química fisiológica puedan investigar al hombre como organismo, en el sentido de las ciencias naturales, no es una prueba a favor de que se roce la esencia del hombre en esto 'orgánico', esto es, en el cuerpo vivo (Leib) explicado científicamente" (Heidegger, M., "Brief über den Humanismus", en: Heidegger, M., Wegmarken, Fráncfort d.M.: Vittorio Klostermann, 1976, p. 324). En efecto, lo que sea el cuerpo en el ser humano es una problemática que solo puede aclararse según su propio modo de ser, el Dasein, pues desde ahí es que se establece la radical diferencia entre su cuerpo y el cuerpo animal. Por tal razón es que Heidegger podrá decir: "El cuerpo del hombre es algo esencialmente distinto a un organismo animal" (ibid).

${ }^{42}$ Heidegger, M., Phänomenologische Interpretation von Kants Kritik der reinen Vernunft, Fráncfort d.M.: Vittorio Klostermann, 1995, p. 86.
} 
Cabe señalar, por otra parte, que en Ser y tiempo es la distinción entre el modo de ser del Dasein y la condición meramente objetual, la Vorhandenheit, el horizonte ontológico para salvaguardar una tematización del existir de modos de ser que no le correspondan ${ }^{43}$. Justamente, la distinción entre ambos modos inconciliables de ser parecen operar en aquellos momentos en los que Heidegger intenta desligarse del problema del cuerpo humano en tanto dimensión orgánico-material ${ }^{44}$. Se trata así de comprender que "Dasein" y "Vorhandenheit" son ante todo modos de ser, y por ende, ambos señalan hacia dos vias distintas en la tematización de un mismo fenómeno. En Zollikoner Seminare parece operar nuevamente dicha distinción: "Ciertamente, lo corporal vivo del Da-sein permite que uno lo vea en esta vida como un objeto material, inerte, como una especie de máquina compleja. Luego, en tal observador lo esencial de lo corporal vivo ha desaparecido para siempre de su mirada"45.

De tal observación debiera advertirse, entonces, que mientras que el fenómeno cuerpo humano puede ser entendido como Leib en intima pertenencia al modo de ser denominado "Dasein", el mismo cuerpo humano, en cuanto Körper, puede ser realzado como "meramente presente" (vorhanden) y, por ello, según un modo de ser inconciliable con el mismo Dasein. En este contexto, se puede comprender que una consideración del cuerpo humano no puede concentrarse en su constitución fisiológica, ya que implicaría una desorientación de aquella mirada que pretende delimitar cómo se es cuerpo en tanto que existente, es decir, desde un modo de ser tan particular como es la apertura de mundo. Por tanto, si la distinción entre Leib y Körper refiere, en sentido estricto, a dos modos de ser, esto pareciera sugerir que el fenómeno integro del cuerpo puede ser realzado, una vez, como mero objeto, y otra, como una instancia del propio existir. Dicho en otros términos, lo que parece señalar la comprensión del cuerpo humano en tanto que Leib no es una dimensión de un cuerpo ahora escindido entre determinadas funciones existenciales y una condición material. La distinción entre Körper y Leib no implica una división del cuerpo óntico en dos ámbitos, sino que ambos, en cuanto maneras de ser, son ante todo categorías según las cuales la corporalidad puede ser iluminada

\footnotetext{
${ }^{43}$ Heidegger, M., Sein und Zeit, pp. 106 y 97.

44 Cf. ibid., p. 56. Asimismo, $c f$. Johnson, F., "La exclusión del cuerpo en Sein und Zeit y la negación de una fenomenología del cuerpo en el pensamiento de Heidegger", en: Revista Pensamiento, 72 (2016).

${ }^{45}$ Heidegger, M., Zollikoner Seminare, p. 293.
} 
en dos direcciones temáticas del todo diferentes ${ }^{46}$. Se trata, entonces, de una inflexión temática según la cual se decidirian sentidos específicos de realce del fenómeno. Esto conduce a pensar, por ende, que la exclusión de la dimensión material en el sentido heideggeriano no implica arrebatar la materialidad al fenómeno del cuerpo, extirpándole sus innegables condiciones fisicas, sino, más bien, radica en hacerlo explícito según el modo en que este se muestra siendo en cuanto Dasein, y mediante el cual una determinada materialidad se presenta ónticamente en un sentido de ser particular ${ }^{47}$. En definitiva, realzar al cuerpo como Leib radica en develar aquel sentido existencial, que no es otro que su carácter ontológico.

Quizás sea justamente el hecho de comprender que un mismo ente puede ser tomado de modo óntico y de modo ontológico la clave para advertir qué se puede decir del cuerpo en cuanto "vivo", es decir, en sus caracteres de ser. En efecto, dos clases de fenómenos parecen anunciarse en las reflexiones de Heidegger, como se menciona en Zollikoner Seminare, donde se distinguirá, por un lado, los fenómenos ónticos, los cuales serian perceptibles, es decir, fenómenos que en concreto estarian siendo (seiende Phänomene), como una mesa, y los fenómenos ontológicos, no perceptibles, y que son previos a la donación de los primeros: "Antes de que podamos percibir la mesa -dice Heidegger- en tanto que esta o aquella mesa, debemos haber percibido previamente que hay algo así como lo presente (Anwesen)"48. Por cierto, dichos fenómenos ontológicos son los que luego serán caracterizados como "posibilidad de ser" (Möglichkeit des Seins) ${ }^{49}$. En definitiva, la mirada existencial, en su esfuerzo por develar los caracteres ontológicos, ha de confrontarse con posibilidades, pues ellas son las que se acusan como rasgos esenciales, es decir, referentes al ser del ente, mientras este es en cuanto ente.

Tal distinción entre fenómenos resulta decisiva para una caracterización del cuerpo humano. Más allá de su constitución orgánica, el auténtico ser del cuerpo ha de entenderse como aquella posibilidad que en su configuración orgánica este se encuentra siendo. Este aspecto metódico es el que pareciera dar el

\footnotetext{
46 Escribano, X., "Poética del movimiento corporal y vulnerabilidad: una reflexión desde la fenomenologia de la enfermedad", en: Revista Co-herencia, 12 (2015), p. 76.

47 Heidegger dirá en sus lecturas sobre Aristóteles: "La mano es primeramente como mano en cuanto viviente, en la medida en que ella pueda agarrar y sentir, y una mano siendo así exige que su hýle sea una determinada, que esté organizada, caracterizada según el determinado ser del poder" (Heidegger, M., Grundbegriffe der aristotelischen Philosophie, p. 233).

${ }^{48}$ Heidegger, M., Zollikoner Seminare, p. 7.

49 Ibid., p. 59.
} 
contexto para que el mismo Heidegger pueda formular el problema del cuerpo en términos eminentemente aristotélicos: "no podemos 'ver', porque tenemos ojos, más bien solo podemos tener ojos, porque somos, de acuerdo a nuestra fundamental naturaleza, entes que ven" ${ }^{50}$. A dicha formulación, por supuesto, pertenecerá la exclusión de la dimensión orgánica como irrelevante para la discusión. Se trata, en efecto, de una exclusión temática que, por ejemplo, puede operar también en una delimitación del acto de oír: "el escuchar es el modo de ser cuerpo, de la participación del ser cuerpo en la conversación"51.

Así, en la consideración esencial de fenómenos corporales ni ojo ni oído parecen ser centrales, pues la estructura ontológica que les hace ser tales no se alberga en la configuración material de los órganos, sino en la dimensión vital en la que se mueve el ser vivo en tanto que "vidente" u "oyente". Justamente, es esta distinción metódica la que se encuentra ya en Aristóteles, cuando afirma: "En efecto, si el ojo fuera el animal, su alma sería la vista" 52 . Dicha "alma", se advierte, sería la condición de que algo así como el globo ocular pueda ser llamado "ojo". El globo ocular, se podría decir, solo es "ojo" realizando, es decir, siendo, la posibilidad de ver. Y, por ende, según lo discutido, es también posible afirmar que son los sentidos de ser del "ver" los que en cada momento se hallan en realización cuando, en términos orgánicos, se muestra un ojo que "mira". Lo que Aristóteles en la cita denomina alma, ha de entenderse, entonces, como la esencia de lo vivo ${ }^{53}$, aquello que Heidegger, por su parte, entenderá como la posibilidad.

En consecuencia, la consideración existencial del cuerpo es una consideración ontológica, y por ende, realza el sentido propio de la posibilidad que le constituye, sin que con ello se niegue su condición orgánica. Por ello, una tematización del cuerpo ha de entenderse como una explicitación de su propio "estar siendo en tanto que existente", es decir, en cuanto la posibilidad que este implica ser, y que se despliega según un modo de ser que es el Dasein mismo. Y esta pareciera ser la razón por la cual puede resultar ahora ilegítimo realzar la existencialidad y considerar a la vez la presencia del órgano. Con ello no se ha comprendido que es el mismo "cuerpo orgánico" el que siempre ha sido objeto de consideración, mas ahora ya no como el órgano con propiedades ónticas,

\footnotetext{
50 Ibid., p. 293.

51 Ibid., pp. 125-126.

52 Aristóteles, Acerca del alma, Madrid: Gredos, 2003, 412b 19-20.

53 Interpretando a Aristóteles, Heidegger dirá: "Psyché es la ousía de un zoon, ella constituye el ser de aquel ente caracterizado como un ser-en-su-mundo (In-seiner-Welt-sein)" (Heidegger, M., Grundbegriffe der aristotelischen Philosophie, p. 168).
} 
sino según su eminente modo de ser "existencial". Por ende, si el niño referido por Boss es tomado como un Dasein particular, el realce de la ausencia de su brazo, en cuando dimensión anatómica, no podría tener lugar en su descripción, ya que con ello se ha confundido el sentido temático, incluyendo uno distinto e inapropiado. Y es que se estaría entendiendo que hay una dimensión existencial y otra material desplegándose paralelamente en tanto que cuerpo, sin atender a que Leib y Körper no son dimensiones ónticas, sino realces formales del mismo fenómeno. He ahí, entonces, la pertenencia de lo orgánico al cuerpo en cuanto Leib. Se trata de una pertenencia ontológica en cuanto lo que ónticamente se muestra en una configuración orgánica específica, está desenvolviéndose en un sentido de ser que es aprehensible formalmente, como sentido dominante de toda su expresión fáctica.

Boss parece, por tanto, entender la distinción Körper-Leib como una escisión en el mismo fenómeno del cuerpo, cuando se trata de que este, en tanto Leib, es tematizado como "perteneciente", es decir, desplegándose según un modo de ser que es el del Dasein mismo. Así, ya podemos observar que, mientras Leib y Körper parecen ser entendidos como instancias ónticas, en el caso de Heidegger ambos términos refieren a dos énfasis formales del mismo fenómeno cuerpo, aunque de acuerdo a dos modos de ser diferentes. Desde esta perspectiva cabe pensar que es la comprensión óntica de la distinción LeibKörper la que parece conducir a Boss a insistir en lo orgánico en sus reflexiones psicológicas, pues, si ambos son entendidos como ámbitos del ente "cuerpo", pese a la primacía de la dimensión existencial sobre la orgánica, esta última no puede ser descartada sin que el fenómeno parezca quedar incompleto en su descripción.

No obstante, a nuestro juicio, dicha lectura óntica de la distinción entre Körper y Leib por parte de Boss no puede ser refutada ponderándola como un mero error. Quizás lo que ocurre es que su propia recepción de la Analítica del Dasein se mueve en motivaciones particulares que justificarian la búsqueda de determinados caracteres humanos que desde Heidegger, sin embargo, no son considerables. Por tanto, la pregunta es: ¿en qué énfasis de lo humano se mueve Boss para que lo orgánico insista en aparecer, partiendo aparentemente de la misma perspectiva del Dasein que Heidegger planteara? ¿No es así que los acentos desde los cuales se realza el fenómeno mismo de lo humano parecen, en uno y en otro caso, haberse modificado? 


\section{Sobre los limites entre la Analitica del Dasein y el Análisis del Dasein}

De acuerdo a lo discutido, la exclusión de lo material en las consideraciones del Dasein no parece ser una dificultad para la tematización ontológica heideggeriana, como sí parece serlo para la reflexión psicológica de Boss, en tanto que este parece entender que Leib y Körper refieren a dos dimensiones ónticas innegables para su praxis psicológica: lo existencial y lo orgánico. Es así como los limites entre ambos programas comienzan a aparecer con mayor claridad. No obstante, para una comprensión acabada de los mismos, cabe preguntar: ¿cuál es aquel fenómeno humano que Boss tiene en vistas en su recepción de la Analítica del Dasein, y que parece distinguirlo de una reflexión eminentemente filosófica?

Destacando la eventual contribución del pensar de Heidegger para una comprensión de las perversiones sexuales, Boss concluye que desde este "se nos ha hecho posible también que nuestros pacientes vivencien la perversa contradicción de su existir total con aquella evidencia y especialmente con aquella conmoción, que cada vez suelen preparar la superación de una mutilación neurótica" ${ }^{44}$. A tal afirmación subyace precisamente aquel punto de partida para abordar ciertas patologias sexuales como el fetichismo. Sin el uso de indumentarias de pieles en el cuerpo de las mujeres, Konrad Schwing quedaba sumido en declarados estados de impotencia sexual ${ }^{55}$. En los términos existenciales en los que Boss intenta entender el caso, se trataria de una relación de culpa con el cuerpo femenino que se fundaria en aquella angustia que "es una totalmente primaria 'disposición afectiva fundamental' del Dasein absoluto (Heidegger)"56. Dicha angustia sería para Boss el fenómeno de base, "inmanente en el Dasein"57 que daría cuenta del fetichismo de Konrad Schwing. Por otra parte, la esquizofrenia no podría entenderse sino como "una perturbación del específico seren-el-mundo" 58 , mientras que las patologías de Regula Zürcher serán pensadas como un ser corporal severamente perturbado al interior de una carencia de libertad de su ser-con-el-otro de realizar su potencial íntegro de amar59.

Es aquí donde se distinguen los programas tanto de Boss como de Heidegger. En el caso de una ontología heideggeriana: “'Ahí’ mienta esta esencial

\footnotetext{
54 Boss, M., Sinn und Gehalt der sexuellen Perversionen, München: Kindler, 1966, p. 172.

5 Cf. ibid., p. 62.

Ibid., p. 64.

57 Ibid.

58 Boss, M., Existential Foundations of Medicine and Psychology, p. 235.

59 Cf. ibid., p. 185.
} 
apertura. Por medio de ella, este ente (el Dasein) está 'ahí' para él mismo en unión con el Da-sein del mundo"60. Así, por lo pronto, se puede advertir que, siendo el Dasein su "apertura" (Erschlossenheit), el fenómeno atendido por las consideraciones heideggerianas parece mostrase como la constitución misma del ahí. Tal pareciera ser, de hecho, el énfasis temático de lo humano que se acusa también en Zollikoner Seminare: “El Dasein trasciende'... En tanto que ser del 'ahí' es la localidad de todo lo que comparece"61. Dicho de otra manera, la problemática del Dasein, cuyo horizonte último es la aclaración del sentido del ser, no pareciera referir sino al fenómeno del existir humano en tanto que sentido fundamental y constituyente de aquella apertura total de mundo que caracteriza a este mismo modo de ser. Considerando lo anterior, entonces, se puede advertir que aquellos momentos constitutivos de lo humano que se realcen en su tematización filosófica, los existenciales, han de considerarse originarios en función de la elucidación de aquel ámbito de apertura, pues esta es la vía para llegar a plantear finalmente una pregunta por el sentido del ser en general ${ }^{62}$. En otras palabras, el ser del hombre ha de ser explorado, desde la mirada existencial heideggeriana, en su relación íntima con el ser, es decir: como el existir en tanto comprensión de ser63.

En el caso del Análisis del Dasein de Boss se advierte, por su parte, una tendencia temática diferente. En cuanto la analítica brinda distinciones para comprender al individuo enfermo ${ }^{64}$, Boss parece recepcionar al Dasein heideggeriano como un nuevo tipo de subjetividad. Una, por cierto, que superaría el reductivo encapsulamiento de una psyche. Se trataría, por decir así, de una subjetividad ahora bien entendida, tras la cual, sin embargo, sigue vigente la noción de una operación de instancias del sujeto en la conformación del mundo, tales como la angustia, el ser-con-el-otro o el desarraigo de la propia libertad inherente al Dasein ${ }^{65}$. Mas dicha tendencia es la que no tiene lugar en las consi-

\footnotetext{
${ }^{60}$ Heidegger, M., Sein und Zeit, p. 132.

61 Heidegger, M., Zollikoner Seminare, p. 240.

62 Cf. Heidegger, M., Sein und Zeit, p. 17.

${ }^{6} \mathrm{Cf}$. Heidegger, M., Zollikoner Seminare, p. 260.

64 En el capítulo XIII de su Fundación existencial de la medicina y la psicología, Boss aborda el concepto de enfermedad como restricción de la apertura del Ahí propio del Dasein, y una consecuente restricción de su libertad ( $c f$. Boss, M., Existential Foundations of Medicine and Psychology, pp. 197-239. Asimismo, cf. Cottier, S. y E. Rohner-Artho , "Der Krankheitsbegriff in der Daseinsanalyse", en: Daseinsanalyse: phänomenologische Anthropologie und Psychotherapie, 7 (1990)) Para una revisión crítica al concepto de enfermedad de Heidegger y Boss ( $c f$. Kouba, P., Geistige Störung als Phänomen, pp.130-173).

${ }^{65}$ Cf. Boss, M., Existential Foundations of Medicine and Psychology, pp. 122-125. También, cf. Heidegger, M., Zollikoner Seminare, p. 202.
} 
deraciones de Heidegger, pues el Dasein en cuanto fenómeno de la apertura del ahí implicaría ir más allá de la noción tradicional de sujeto. Los existenciales, lejos de ser realzados como instancias psicológicas, son el intento de dejar de lado la noción de subjetividad. “Dasein-subraya Heidegger- no es 'sujeto'. No hay más pregunta sobre la subjetividad. Trascendencia no es 'estructura de la subjetividad', sino su supresión (Beseitigung)"66. Asimismo, dicha ampliación del fenómeno desde un mero sujeto al Dasein es la que parece advertirse también en la determinación de su ser en cuanto cuidado (Sorge), es decir, en cuanto un "anticiparse-estando-ya-en-(el-mundo) en cuanto estar-junto-a (entes intramundanos comparecientes)"67. Como aquí se observa, la presencia del ente intramundano mismo es concebida al interior de la apertura que el Dasein es, en tanto que su presencia se realiza como su descubrimiento (Entdecktheit)68. Pues bien, si el Dasein fuese meramente un sujeto, la integración del mundo al mismo difícilmente podría justificarse, ya que un sujeto, en términos tradicionales, no es un concepto que integre lo que este no es: su mundo. Por tanto, y a diferencia de Boss, en el caso de Heidegger la noción de sujeto no solo parece ser ampliada para integrar al mundo mismo, sino que dicha ampliación, según él lo entiende, sería su superación.

Es aquí donde se hacen evidentes los limites entre la Analítica del Dasein heideggeriana y el análisis del Dasein de Boss. Límites cuya naturaleza es preciso ahora esclarecer. Para ello, la pregunta es: ¿qué es lo que permite en concreto la recepción por parte de Boss del Dasein como un sujeto? Quizás la respuesta pueda hallarse en una observación que el mismo Heidegger hace a los psiquiatras: "Ejercemos psicología, sociología, psicoterapia para ayudar al hombre, para que el hombre gane la meta de la adaptación y de la libertad en sentido amplio"69. ¿No se trata, pues, para Boss de haber hallado en la analítica una base conceptual que haga efectiva tal ayuda al hombre? Y cuándo se habla aquí de ayudar, ¿no se mienta un auxilio siempre de la individualidad humana? Pues bien, al igual que en su obra principal ${ }^{70}$, en Impulsos de Martin Heidegger para una otra psiquiatría, Boss seguirá indagando sobre casos psiquiátricos que, desde Heidegger, podrian clarificarse ahora según cuatro tipos distintos de instancias existenciales: enfermedades respecto del ser-cuerpo,

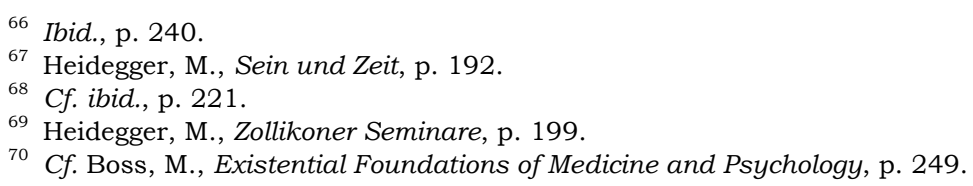


trastornos del espaciarse y temporizarse del ser-en-el-mundo, perturbaciones del estar dispuesto afectivamente, y restricciones de la apertura y libertad del Dasein $^{71}$. Dicho intento de aclaración respecto de las patologías psiquiátricas parece confirmar, en efecto, una motivación terapéutica desde la cual Boss quiere acceder a lo humano, y ciertamente, en este contexto, no puede tratar al hombre como comprensor del ser y constituidor de mundo, sino, más bien, ha de concebirlo siempre como el individuo concreto que requiere ser guiado a su propia salud 72 .

Así, es en este énfasis de lo humano en cuanto individuo donde la dimensión orgánica adquiere su pleno derecho de ser considerada. Y es que el cuerpo orgánico ha de ser tema para la psicoterapia daseinsanalítica, en cuanto se ocupa de sujetos particulares, para atender a sus propios trastornos. Esta, al igual que otras, es una dimensión efectiva e innegable en el interior de la problemática del sujeto enfermo y, por lo mismo, necesariamente atendible. En términos programáticos, se podría afirmar que el campo de estudio propio de la psicología terapéutica sigue siendo uno tal que no puede marginar dimensión humana alguna, incluyendo la corporal, pues para ella siempre se trata de un auxilio de la condición humana integra. Con esto se puede apreciar, en fin, que la motivación terapéutica de Boss es la que ha hecho énfasis en lo humano como un sujeto concreto y la que parece también guiar una lectura óntica de la distinción Körper-Leib, en cuanto es el sujeto y su individualidad el horizonte que anima su recepción.

No obstante, en el caso de Heidegger, y en vistas a su ocupación con la pregunta por el sentido del ser, el cuerpo podría ser tratado solo como constitutivo de la apertura del propio ahí, es decir, como componente de esta relación al mundo ek-stática ${ }^{73}$. Por ello, lo orgánico, como discutiamos, sí puede ser dejado de lado, pues, las características del globo ocular, por ejemplo, no constituyen una dimensión de tal fenómeno, como sí ocurre con los caracteres de la vista, en tanto donadora del ente del mundo, como Heidegger lo destacaba de Kant. En consecuencia, son las diferencias ante todo entre las motivaciones que subyacen a Heidegger y a Boss las que los conducen finalmente a énfasis radicalmente

\footnotetext{
${ }^{71}$ Cf. Boss, M., "Anstösse Martin Heideggers für eine andere Psychiatrie”, en: Hans-Helmuth Gander (ed.), Von Heidegger her: Messkircher Vorträge, Fráncfort d.M.: Vittorio Klostermann, 1991, p. 126.

${ }^{72}$ Cf. Wucherer-Huldenfeld, A., "Die Weite des menschlichen Da-seins in ihrer Bedeutung für die Psychotherapie", en: Daseinsanalyse: phänomenologische Anthropologie und Psychotherapie, $10 / 1$ (1993).

${ }^{73}$ Cf. Heidegger, M., Zollikoner Seminare, p. 258.
} 
distintos de tematización de lo humano, donde problemáticas que parecieran competerle a ambos, como sería lo orgánico, solo lo harán en apariencia.

Pues bien, resulta interesante notar cómo es que la aparición de lo orgánico en las consideraciones de un Boss que pretende reformular la psicología desde la Analitica del Dasein se ha vuelto aquel punto problemático concreto desde el cual se hace patente la pugna entre dos programas de investigación distintos. La presencia de lo orgánico se mostró como la auténtica expresión de una oposición que no tiene su origen en las doctrinas desarrolladas por Heidegger y Boss, sino en aquello que las anima. El problema de lo orgánico ha sido, pues, el inicio para detectar que ambas se despliegan por vías distintas, porque sus motivaciones les singularizan y les proyectan hacia uno $u$ otro énfasis temático. Así, los límites entre los programas de Heidegger y Boss exhiben una naturaleza tan particular como ser, en efecto, aquellas motivaciones según las cuales ambos abordan lo humano. De esta manera, y para concluir, sería importante reflexionar sobre lo que finalmente implicaría pensar en tales motivaciones como aquellos límites entre ambos.

Pero, ¿qué es lo que caracteriza al límite? Quizás algunas indicaciones de Welte puedan ayudarnos en esta última reflexión. Desde él oímos que el límite separa determinando. Esto es, su separación implica que los elementos puestos en relación mediante él se den ya en determinaciones, vale decir, posicionados en su propia especificidad. El limite es, a la vez, distinctio y positio: este delimita distinguiendo. Empero, tal escisión particularizadora que constituye al límite es también una vinculación. A la esencia del límite corresponderia, en efecto, ser una "distinción, que en todas partes unifica" ". Siendo disjunctio y positio, el límite sería también conjunctio. Así, las motivaciones que animan el pensar tanto de Heidegger como de Boss parecen igualmente indicar, en cuanto límites, una disyunción que, por cierto, es aquella según la cual hemos distinguido las respectivas particularidades de sus naturalezas temáticas. Mas, exponiendo tales motivaciones en tanto que disjunctio y positio, restaría examinar aún qué implica para la discusión sobre los límites entre la Analítica del Dasein y el Análisis del Dasein, que estas sean además una conjunctio.

¿Hay, empero, algo común entre ambas? Tal vez la respuesta radique ante todo en identificar el objeto mismo de ambas motivaciones, a saber, el hombre, pues es dicho ente tan particular el que ha sido en todo momento tema de un programa filosófico como el heideggeriano y de uno psicológico como el

${ }^{74}$ Welte, B., "Die Grenzen im Leben der Wissenschaften", en: Freiburger Dies Universitatis: Bedeu-
tung und Funktion der Grenze in den Wissenschaften, 6 (1958), p. 13. 
de Boss. Mas, ¿qué es lo que finalmente lleva a ambos a preguntar por este? No pareciera del todo inadecuado afirmar que ni la filosofia ni la psicología en cuanto tales podrían descuidarlo, puesto que ambas parecen reflejar la aspiración a un conocimiento radical de nosotros mismos, para garantizar la posibilidad de una orientación genuina respecto de nuestro entorno, del otro, como del existir humano particular. Ya sea Heidegger, mediante la aclaración radical del Dasein en vistas a la pregunta por el ser, o Boss, ocupado del existir para acceder adecuadamente a situaciones inmersas en trastornos vitales, a ambos les une la pretensión de apropiarse de lo humano, donde sus respectivas motivaciones se mancomunan. Ellas, en tanto motivaciones humanas, no hacen sino expresar la urgencia tan propiamente humana como es preguntar por nosotros mismos y nuestra condición fáctica. Y es por la vía de comprender ahora tales límites en dicha unión que la problemática presencia de lo orgánico que hemos discutido señala todavía un último aspecto a considerar.

Se ha dicho que para el pensar ontológico heideggeriano, la dimensión orgánica puede quedar de lado, en vistas al realce formal del ser que este exhibe, mientras se despliega ónticamente. Mas, es probable que sea en este punto donde tal pensar corra el riesgo de acabar insensible a una problemática que, en la tendencia óntica de la psicoterapia de Boss, aparece con suma evidencia. Si lo orgánico en Boss, podríamos decir, insiste en aparecer, no parece ser por lo orgánico mismo, sino por una experiencia vital que le constituye y que es tema de su propia ocupación terapéutica. En efecto, son esas enfermedades psicosomáticas y somatogenéticas las que no dejan de mostrar a aquella terapia psicológica que busca su salud una dimensión orgánica a la que pertenece cierta fragilidad, esto es, cierta vulnerabilidad, que en todo momento parece dejar abierta la posibilidad de que el sujeto pueda extraviarse en contextos vitales del más profundo dolor. Dicha vulnerabilidad de lo orgánico, como se observa en los trastornos de Regula Zürcher, no deja de denunciar una condición existencial que debiera ser entendida ante todo como constitutiva de lo humano y, podemos decir, que parece ser aquella experiencia vital muda, que anónimamente nutre y sigue fomentando que lo orgánico se acuse insistentemente a una consideración psicológica que, empero, ha pretendido asumir un pensar existencial que expresamente le posterga. Y si esto fuese así, cabria preguntar: ¿es la vulnerabilidad que delata lo orgánico un fenómeno reducible sin más a un "ser para la muerte", en términos heideggerianos? ${ }^{75} ¿^{O} \mathrm{O}$ tal vulnerabilidad

${ }^{75}$ Cf. Torralba, F., "Hacia una antropología de la vulnerabilidad", en: Revista Forma, 2 (2010), p. 27. 
propia del individuo enfermo posee caracteres fenoménicos propios y, por ende, evidencia una dimensión del ser humano que aún debiese ser indagada existencialmente? Y, más aun, ¿no sería posible pensar que dicha vulnerabilidad también es una instancia tan propia de nuestro existir que sí puede ser, a su vez, indagada como un momento del aparecer del ente circundante con el cual la vida concreta se confronta a diario y, asimismo, como constitutiva del comparecer del otro?76

Tales preguntas pueden quedar acá solo planteadas, pues su respuesta implica discusiones del todo distintas a las presentes, pero la posibilidad de su simple detección y formulación ya parece ser una ganancia. Se advierte acá que desde una confrontación con la concretud óntica humana, como es la psicología terapéutica de Boss, se continúan proponiendo problemáticas existenciales relevantes para el mismo proyecto filosófico existencial, como parece ser esta vulnerabilidad inherente al sujeto enfermo. Si este fuese el caso, entonces, estas reflexiones parecen advertir que lo orgánico no es tan fácilmente prescindible, ni para la psicologia, en cuanto auxilio del individuo vulnerable, ni tampoco, y pese a la posición de Heidegger, para la filosofia, pues revela instancias vitales que pueden ser examinadas como constitutivas del existir en su mundo. Por tanto, la discusión sobre los limites entre los programas de Boss y Heidegger parece ahora no concluir solo distinguiendo y separando sus énfasis temáticos. En cuanto ambos se conjugan en la pretensión de una comprensión genuina de lo humano, es la problemática aparición de lo orgánico la que sigue sugiriendo tareas que, siendo asumidas por el primero, reclaman aún la atención del segundo.

Recibido: $31 / 07 / 2016$

Aprobado: 28/04/2017

\footnotetext{
${ }^{76}$ Escribano (2015) refiere la vulnerabilidad del sujeto enfermo desde el fenómeno del cuerpo vivo. El hecho de que sus reflexiones no contemplen la Analitica del Dasein de Heidegger es un indice, a nuestro juicio, de que ella misma supone ya una exclusión de raíz de tal problema. Es la psiquiatria la que, posicionándose en una óptica existencial, insistirá en señalar aquella vulnerabilidad ausente en el pensar de Heidegger ( $c f$. Kettner, M., "Philosophische Behandlung von Psychotherapie-Indikationen, Risiken und Nebenwirkungen", en: Psychotherapeutenjournal, 3 (2013), p. 240).
} 


\section{Bibliografia}

Aristóteles, Acerca del alma, Madrid: Gredos, 2003.

Askay, R., "La filosofia de Heidegger y sus implicaciones para la psicología: Freud y el psicoanálisis existencial", en: Gaceta Universitaria, 2 (2006).

Boss, M., Der Traum und seine Auslegung, Bern/Stuttgart: Hans Huber, 1953.

Boss, M., "The ego? Human Motivation?”, en: Acta Psychologica, 19 (1961). https://doi. org/10.1016/S0001-6918(61)80082-6

Boss, M., "The Conception of Man in Natural Science and Daseinsanalysis", en: Comprehensive Psychiatry: Official Journal of the American Psychopathological Association, $3 / 4$ (1962). https://doi.org/10.1016/S0010-440X(62)80021-2

Boss, M., Sinn und Gehalt der sexuellen Perversionen, München: Kindler, 1966.

Boss, M., Existential Foundations of Medicine and Psychology, Conway, S. y A. Cleaves (trads.), Nueva York/Londres: Jason Aronson, 1983.

Boss, M., "Anstösse Martin Heideggers für eine andere Psychiatrie”, en: Gander, H.H., (ed.), Von Heidegger her: Messkircher Vorträge, Fráncfort d.M.: Vittorio Klostermann, 1991.

Becker, G., Philosophische Probleme der Daseinsanalyse von Medard Boss und ihre praktische Anwendung, Marburgo: Tectum Verlag, 1997.

Cottier, S. y E. Rohner-Artho, "Der Krankheitsbegriff in der Daseinsanalyse", en: Daseinsanalyse: phänomenologische Anthropologie und Psychotherapie, 7 (1990). https://doi.org/10.1159/000456304

Dastur, F. y P. Cabestan, Daseinsanalyse, Paris: Vrin, 2011.

Escribano, X., "Poética del movimiento corporal y vulnerabilidad: una reflexión desde la fenomenología de la enfermedad”, en: Revista Co-herencia, 12 (2015). https:// doi.org/10.17230/co-herencia.12.23.3

Heidegger, M., "Brief über den Humanismus”, en: Heidegger, M., Wegmarken, Fráncfort d.M.: Vittorio Klostermann, 1976.

Heidegger, M., Zollikoner Seminare, Fráncfort d.M.: Vittorio Klostermann, 1994.

Heidegger, M., Phänomenologische Interpretation von Kants Kritik der reinen Vernunft, Fráncfort d.M.: Vittorio Klostermann, 1995.

Heidegger, M., Sein und Zeit, Tubinga: Max Niemeyer Verlag, 2001.

Heidegger, M., Grundbegriffen der aristotelischen Philosophie, Fráncfort d.M.: Vittorio Klostermann, 2002.

Heidegger, M., Die Grundbegriffe der Metaphysik: Welt-Endlichkeit-Einsamkeit, Fráncfort d.M.: Vittorio Klostermann, 2004.

330 Heidegger, M., Metaphysische Anfangsgründe der Logik, Fráncfort d.M.: Vittorio Klostermann, 2007.

Johnson, F., "La exclusión del cuerpo en Sein und Zeit y la negación de una fenomenología del cuerpo en el pensamiento de Heidegger", en: Revista Pensamiento, 72 (2016). https://doi.org/10.14422/pen.v72.i270.y2016.008

Kettner, M., "Philosophische Behandlung von Psychotherapie-Indikationen, Risiken und Nebenwirkungen", en: Psychotherapeutenjournal, 3 (2013). 
Kouba, P., Geistige Störung als Phänomen. Perspektiven des heideggerschen Denkens auf dem Gebiet der Psychopathologie, Würzburg: Königshausen \& Neumann, 2012.

Stüttgen, T., "Zur Unterscheidung von Körperlichkeit und Leib”, en: Daseinsanalyse: phänomenologische Anthropologie und Psychotherapie, 7 (1990).

Torralba, F., "Hacia una antropología de la vulnerabilidad", en: Revista Forma, 2 (2010).

Welte, B., "Die Grenzen im Leben der Wissenschaften", en: Freiburger Dies Universitatis: Bedeutung und Funktion der Grenze in den Wissenschaften, 6 (1958).

Wucherer-Huldenfeld, A., "Die Weite des menschlichen Da-seins in ihrer Bedeutung für die Psychotherapie", en: Daseinsanalyse: phänomenologische Anthropologie und Psychotherapie, 10/1 (1993). https://doi.org/10.1159/000456402 